\title{
THE RHEOLOGY OF A CEMENT PASTE AND THE FROST RESISTANCE OF A PERMEABLE CONCRETE WITH AN EMULSIFIED ASPHALT MODIFIED BY A SILANE COUPLING AGENT
}

\author{
"ZHEN YAN*, " LAIBO LI*, MINGXU CHEN*, "LINGCHAO LU*, **, PIQI ZHAO**, XIN CHENG*, ** \\ *School of Materials Science and Engineering, University of Jinan, \\ Jinan 250022, China \\ **Shandong Provincial Key Lab. of Preparation and Measurement of Building Materials, University of Jinan, \\ Jinan 250022, China
}

"E-mail: yanzhen_ujn@163.com, lingchao_lu@163.com

Submitted September 19, 2019; accepted November 4, 2019

\begin{abstract}
Keywords: Permeable concrete, Silane coupling agent, Emulsified asphalt, Frost resistance, Compressive strength
Permeable concrete has been widely used in infrastructure constructions due to its excellent water permeability and environmental protection function. In this paper, a silane coupling agent (SCA) was utilised to modify a cement paste and permeable concrete with an emulsified asphalt (EA) for improving the workability of the cement paste and the frost resistance of the permeable concrete. A rheometer was used to characterise the rheological properties of the cement paste. The results of the experiment suggested that the hysteresis loop area of the cement paste increased $10.2 \%$ to a value of $22739 \mathrm{~Pa} \cdot \mathrm{S}^{-1}$, proving that the utilisation of the SCA was suitable to enhance the workability of the cement paste with the EA. The frost resistance of the permeable concrete increased $4.2 \%$ while its 120-day dry shrinkage reduced $40.7 \%$. In addition, the bonding strength of the cement paste and the 28-day compressive strength of the permeable concrete increased $40.7 \%$ and $61.4 \%$ by the $0.14 \%$ $S C A$, respectively. Furthermore, the difference of the total void ratio and interconnected void ratio of the permeable concrete was reduced by the SCA, which suggested the utilisation of the SCA was beneficial in ensuring the mechanical properties and water permeability of the concrete.
\end{abstract}

\section{INTRODUCTION}

Concrete is the most widely used material in construction and civil areas. For normal concrete, urban ecological problems, such as the 'heat island effect' [1-4], inland inundation [5,6] and water and soil erosion [7], also occur frequently due to the application of normal concrete. Therefore, a functional concrete with excellent water permeability was purposed to overcome the shortcomings of concrete as described above, and it has been appropriately named as 'permeable concrete'.

Permeable concrete is an important green building material, which conforms to the concept of a 'sponge city' [8]. The use of permeable concrete can increase the water and air permeability and reduce the surface temperature and mitigate the 'heat island effect' of the urban infrastructure due to its absorption capacity for the harmful ions [9-11]. In addition, the use of permeable concrete can also effectively solve the problem of water pollution [12]. Furthermore, the amount of cement used in the permeable concrete production is lower than that of ordinary concrete, which can reduce the consumption of energy and the emission of $\mathrm{CO}_{2}$ [13-15]. Owing to its excellent performance, permeable concrete has been widely used in slope protection, parking lots and sidewalks $[16,17]$.
Although permeable concrete has many excellent properties, the disadvantage of poor frost resistance hinders its widespread application and development. Therefore, there many scholars have focused on the frost resistance of permeable concrete. A previous investigation showed that admixing with a silica fume or fibre or increasing the cement content could improve the frost resistance of the permeable concrete [18]. The study of Dalibor K. et al. [19] showed that the grain size distribution of the coarse aggregate has an influence on the frost resistance and mechanical properties of permeable concrete. Hao W. et al. [20] investigated the properties of permeable concrete, especially the frost resistance, which suggested that ethylene-vinyl acetate (EVA) latex and polypropylene (PP) fibres could significantly improve the frost resistance owing to the enhancement of the interfacial bonding on the cementitious matrix. Therefore, organics have often been used to enhance the frost resistance of the permeable concrete. Similarly, emulsified asphalt (EA), as a kind of organic, was commonly used to improve the frost resistance of concrete. The work by Lahdensivu J. et al. [21] on the durability of asphalt concrete suggested that the asphalt could improve the durability of the concrete. Therefore, EA was adopted to increase the frost resistance of the permeable concrete in this study. EA is a liquid asphalt 
Yan Z., Li L., Chen M., Lu L., Zhao P., Cheng X.

that produces oil-in-water under the special process of the asphalt and emulsifier. It is a kind of road building material with low viscosity and good fluidity at normal temperatures. However, the mechanical properties (e.g., compressive strength, flexural strength) of the concrete decreases with an increase in the EA, while the frost resistance is improved by the EA. At the same time, the mismatch between the cement and the EA can be mitigated by a silane coupling agent (SCA) due to the fact that the SCA can insert the zone in between the organic and inorganic formed an "organic matrix-SCAinorganic matrix" bonding layer. According to the theory, SCA has been utilised to contact the cement particles and the EA, the same as a bridge. Hence, SCA has been used to modify the EA in order to improve the frost resistance and mechanical properties in this paper.

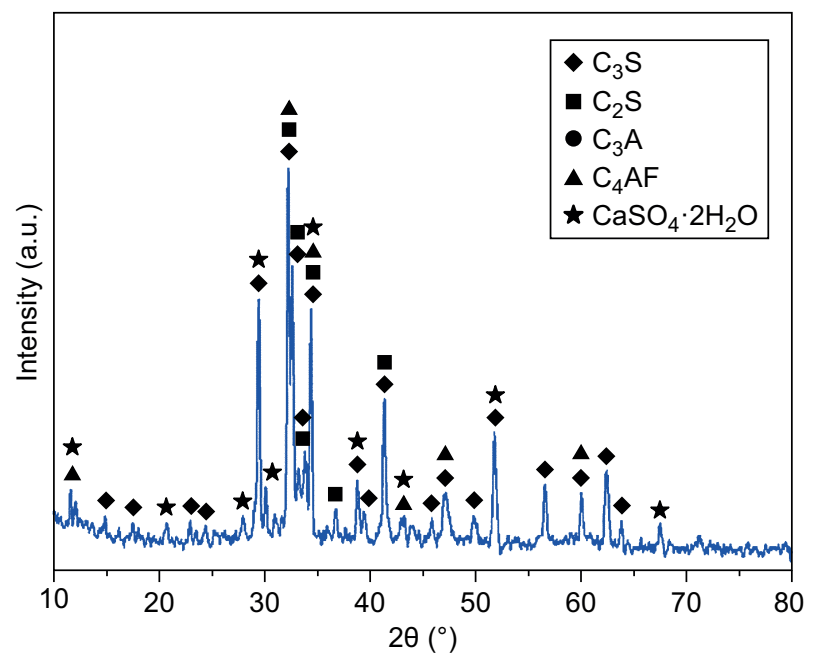

Figure 1. The XRD analysis of the OPC.
In this paper, EA has been adopted to improve the frost resistance of the permeable concrete, and SCA has been used to modified to enhance the EA to improve the combination between the EA and the cement paste in order to ensure the mechanical properties of the permeable concrete. The properties of cement paste and the permeable concrete, especially the rheological properties of the cement paste and the resistance of the permeable concrete, have been investigated. Another im-portant purpose of this paper is to offer useful data for improving the development of the permeable concrete industry.

\section{EXPERIMENTAL}

\section{Raw materials}

Ordinary Portland cement (OPC, Grade 42.5R according to the Chinese National Standards GB 175-2007 [22], manufactured in the Qufu Branch of CUCC, China) was used as the main cementitious material. The X-ray diffraction analysis (XRD, Advanced D8, Germany) and quantitative X-ray diffraction (QXRD) were employed to analyse the phases of the OPC, and the result is presented in Figure 1 and Table 1. The particle size distribution of the OPC was determined using a laser particle size analyser (LS13320, USA) and is shown in Figure 2. The chemical compositions of the OPC were measured by an X-ray fluorescence spectrometer (XRF, Tiger S8, Germany), and the physical properties of it were tested according to GB 175-2007 [22], as shown in Table 2 and Table 3. The limestone (manufactured in the Chang Qing Concrete Supplier Co., Ltd, China) with a diameter of 8 - $11 \mathrm{~mm}$ was used as the aggregate, the physical properties of it were given in Table 4.

Table 1. The mineralogical compositions of the OPC (\%).

\begin{tabular}{lcccccc}
\hline Mineral & $\mathrm{C}_{3} \mathrm{~S}$ & $\mathrm{C}_{2} \mathrm{~S}$ & $\mathrm{C}_{3} \mathrm{~A}$ & $\mathrm{C}_{4} \mathrm{AF}$ & $\mathrm{CaSO}_{4} \cdot \frac{1}{2} \mathrm{H}_{2} \mathrm{O}$ & Amorphous \\
\hline Content & 46.64 & 10.96 & 4.30 & 5.39 & 3.10 & 28.75 \\
\hline
\end{tabular}

Table 2. The chemical compositions of the OPC (wt. \%).

\begin{tabular}{lccccccccc}
\hline Oxide & $\mathrm{CaO}$ & $\mathrm{SiO}_{2}$ & $\mathrm{Fe}_{2} \mathrm{O}_{3}$ & $\mathrm{Al}_{2} \mathrm{O}_{3}$ & $\mathrm{MgO}$ & $\mathrm{SO}_{3}$ & $\mathrm{Na}_{2} \mathrm{O}$ & $\mathrm{K}_{2} \mathrm{O}$ & $\mathrm{LOI}$ \\
\hline Content & 51.01 & 21.74 & 3.42 & 8.55 & 3.30 & 3.14 & 0.26 & 0.65 & 2.82 \\
\hline
\end{tabular}

Table 3. The physical properties of the OPC.

\begin{tabular}{|c|c|c|c|c|c|c|c|}
\hline \multirow[t]{2}{*}{ Properties } & \multirow{2}{*}{$\begin{array}{l}\text { Density } \\
\left(\mathrm{g} \cdot \mathrm{cm}^{-3}\right)\end{array}$} & \multirow{2}{*}{$\begin{array}{l}\text { Normal consistency } \\
(\%)\end{array}$} & \multirow{2}{*}{$\begin{array}{l}\text { Surface area } \\
\qquad\left(\mathrm{m}^{2} \cdot \mathrm{kg}^{-1}\right)\end{array}$} & \multicolumn{2}{|c|}{$\begin{array}{l}\text { Setting time } \\
(\min )\end{array}$} & \multicolumn{2}{|c|}{$\begin{array}{c}\text { Compressive strength } \\
(\mathrm{MPa})\end{array}$} \\
\hline & & & & Initial setting & $\overline{\text { Final setting }}$ & $3 d$ & $28 \mathrm{~d}$ \\
\hline Results & 3.13 & 28.4 & 317 & 218 & 319 & 26.6 & 48.3 \\
\hline
\end{tabular}

Table 4. The physical properties of the aggregate.

\begin{tabular}{lcccc}
\hline Properties & $\begin{array}{c}\text { Apparent density } \\
\left(\mathrm{kg} \cdot \mathrm{m}^{-3}\right)\end{array}$ & $\begin{array}{c}\text { Grain size } \\
(\mathrm{mm})\end{array}$ & $\begin{array}{c}\text { Crushing index } \\
(\text { wt. \%) }\end{array}$ & $\begin{array}{c}\text { Water absorption } \\
(\text { wt. \%) }\end{array}$ \\
\hline Results & 2730 & $8-11$ & 4.8 & 1.76 \\
\hline
\end{tabular}


The rheology of a cement paste and the frost resistance of a permeable concrete with an emulsified asphalt modified...

The physical properties of the EA (manufactured in the Jinan Huanghe Luqiao Construction Group Co., Ltd, China) are given in Table 5. The SCA (manufactured in the Shengbin Chemical Co., Ltd of Tianjin, China) was adopted to enhance the bonding between the ce-

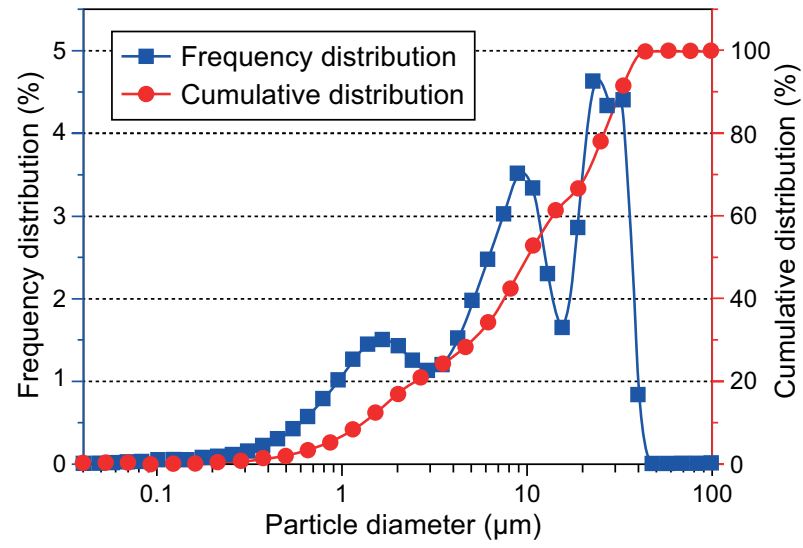

Figure 2. The particle size distribution of the OPC. ment paste and the EA. The SCA used in this paper was KH550. A polycarboxylate polymer (PP, Shandong Academy of Building Research, China) was used as the superplasticiser, and its physical properties are presented in Table 6.

\section{The orthogonal test design} and sample preparation

The work of the permeable concrete modified by the EA suggested that the optimal OPC:EA was 1000:70 [32]. In this paper, $0.07 \%$ (by the mass of the cement, is as follows), $0.14 \%, 0.21 \%, 0.28 \%$ and $0.35 \%$, KH550 were add into the cement paste at the OPC:EA of 1000:70, and marked as SC-K1, SC-K2, SC-K3, $\mathrm{SC}-\mathrm{K} 4, \mathrm{SC}-\mathrm{K} 5$, SC-K6. The cement paste with $0 \%$ KH550 was used as the reference, and marked as SC-K0. The composite of the cement pastes is presented in Table 7. The mixing procedure of the cement paste, in details, is as follows:

Table 5. The physical properties of the EA.

\begin{tabular}{lccccc}
\hline Properties & Ion-type & $\begin{array}{c}\text { Solid content } \\
(\%)\end{array}$ & $\begin{array}{c}\text { Viscosity } \\
(\mathrm{Pa} \cdot \mathrm{s})\end{array}$ & $\begin{array}{c}\text { Penetration } \\
(\mathrm{mm})\end{array}$ & $\begin{array}{c}\text { Softening point } \\
\left({ }^{\circ} \mathrm{C}\right)\end{array}$ \\
\hline Results & Anion & 94.5 & 6.8 & 6.7 & 43.1 \\
\hline
\end{tabular}

Table 6. The physical properties of the PP.

\begin{tabular}{lcccc}
\hline Properties & $\begin{array}{c}\text { Reduction efficiency } \\
(\%)\end{array}$ & $\begin{array}{c}\text { Density } \\
\left(\mathrm{g} \cdot \mathrm{cm}^{-3}\right)\end{array}$ & $\mathrm{pH}$ & $\begin{array}{c}\text { Solid content } \\
(\%)\end{array}$ \\
\hline Results & 28 & 1.073 & 6.3 & 25.12 \\
\hline
\end{tabular}
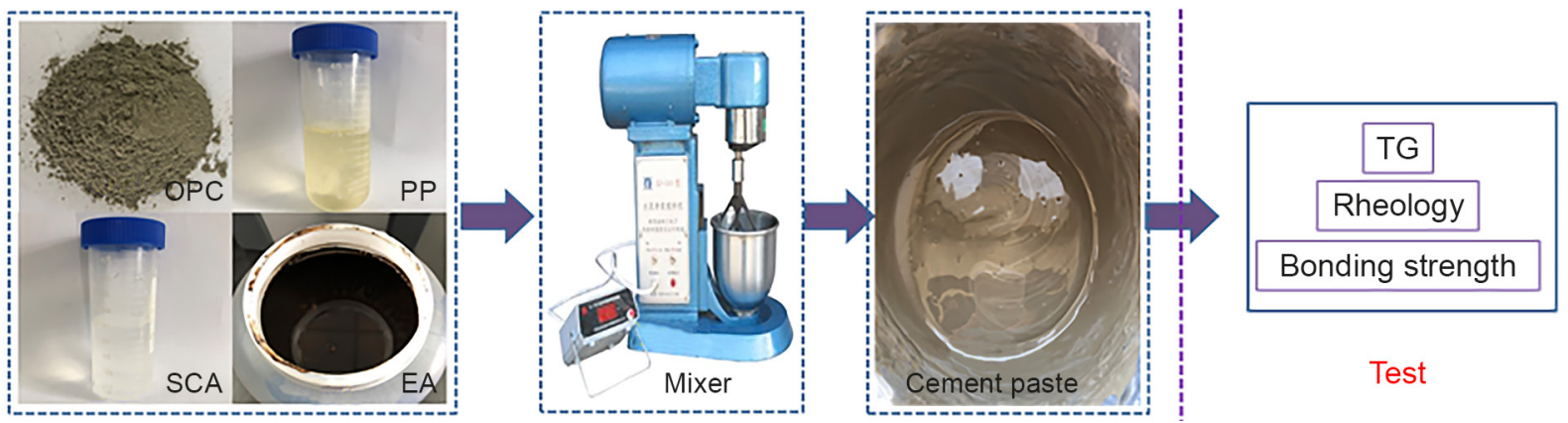

a) Cement paste preparation process

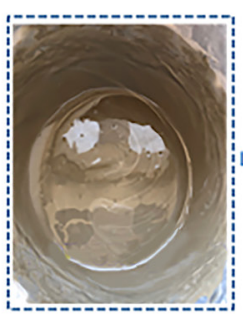

Cement paste
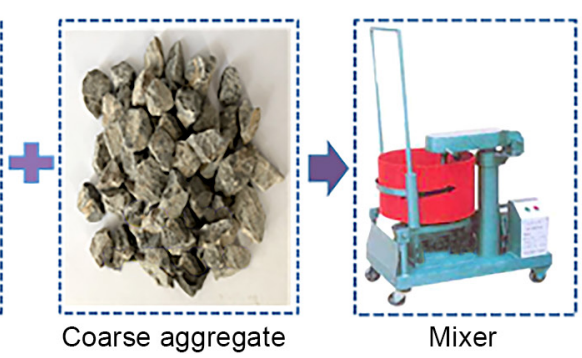

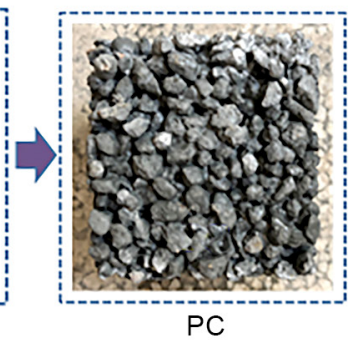

PC

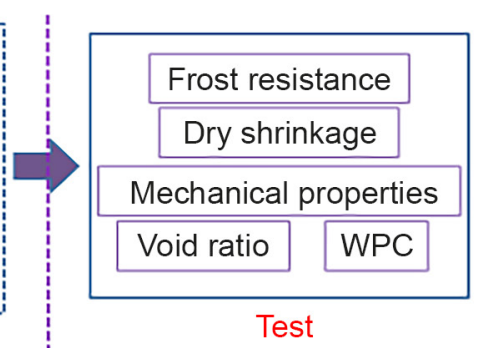

Test

b) Permeable concrete preparation process

Figure 3. The preparation of the cement paste (a) and the preparation of the permeable concrete (b). 
Yan Z., Li L., Chen M., Lu L., Zhao P., Cheng X.

Table 7. The composition of the cement pastes $(\mathrm{kg})$.

\begin{tabular}{lcccccc}
\hline Sample number & SC-K0 & SC-K1 & SC-K2 & SC-K3 & SC-K4 & SC-K5 \\
\hline KH550 & 0 & 0.7 & 1.4 & 2.1 & 2.8 & 3.5 \\
PP & 1.02 & 1.02 & 1.02 & 1.02 & 1.02 & 1.02 \\
EA & 70 & 70 & 70 & 70 & 163 & 70 \\
Water & 163 & 163 & 163 & 1000 & 163 & 163 \\
OPC & 1000 & 1000 & 1000 & & 1000 & 1000 \\
\hline
\end{tabular}

- the KH550 and the mixing water were mixed together in a mixer for $3 \mathrm{~min}$;

- the PP was added into the mixer and further mixed for another $30 \mathrm{~s}$;

- the OPC was added into the mixer for the next $120 \mathrm{~s}$.

The preparation of the cement paste is shown in Figure $3 \mathrm{a}$.

The cement paste, as described above, and the coarse aggregate were adopted to prepare the permeable concrete using a concrete mixer. The paste-aggregate ratio was 0.22 , and marked as PC-K0, PC-K1, PC-K2, PC-K3, PC-K4, PC-K5, PC-K6. Then, the fresh permeable concrete was cast into cuboid moulds $(100 \times 100 \times 100 \mathrm{~mm}$, $100 \times 100 \times 400 \mathrm{~mm}$ and $100 \times 100 \times 515 \mathrm{~mm})$ and cylindrical moulds (diameter $100 \mathrm{~mm}$, height $200 \mathrm{~mm}$ ), and were consolidated by an electric vibrator. The moulded specimens were then put in a curing environment of $20 \pm 2{ }^{\circ} \mathrm{C}$ and $95+5 \% \mathrm{RH}$ (relative humidity). After 24 hours, the specimens were placed under water at $20 \pm$ $2{ }^{\circ} \mathrm{C}$ for another 2 days and 27 days. The preparation of the cement paste is presented in Figure $3 \mathrm{~b}$.

The properties being tested and the material properties

\section{The rheological properties}

The rheological properties of the cement paste, such as the shear stress, shear rate and apparent viscosity, were measured by a rheometer (Kinexus $\mathrm{Lab}+, \mathrm{UK}$ ).

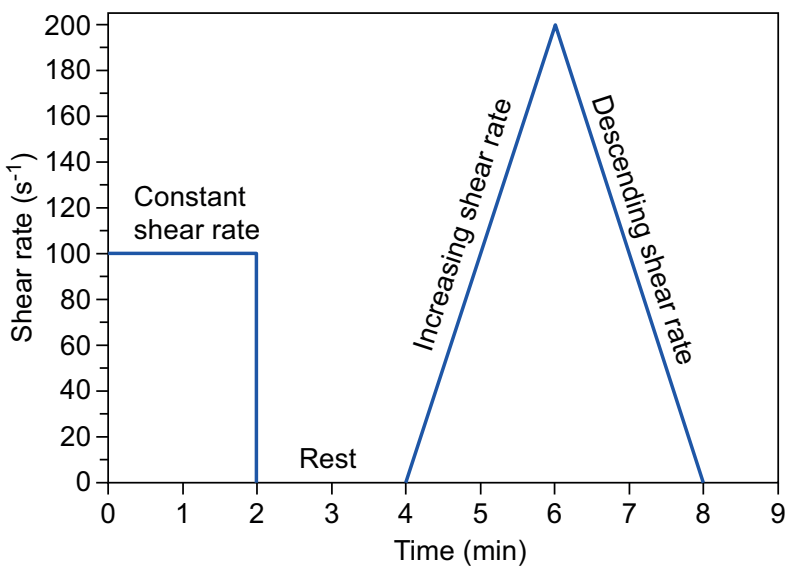

Figure 4. The rheology measurement procedure of the cement paste.
The procedure for the measurement of the rheological properties of the cement paste is shown in Figure 4. The rheological properties of the fresh cement paste were measured with a constant shear rate of $100 \mathrm{~s}^{-1}$ in the first $2 \mathrm{~min}$, followed by $2 \mathrm{~min}$ of rest. Then, the cement paste had an increasing shear rate from 0 to $200 \mathrm{~s}^{-1}$ for $2 \mathrm{~min}$ and a descending shear rate for $2 \mathrm{~min}$.

\section{The TG analysis}

The thermo-gravimetric (TG) curve was collected by a simultaneous thermal analysis instrument (TGA/1600HT, Switzerland) in a temperature range of $30-1000{ }^{\circ} \mathrm{C}$ with an increasing heat rate of $10^{\circ} \mathrm{C} \cdot \mathrm{min}^{-1}$ and the flow rate of the argon gas was $50 \mathrm{ml} \cdot \mathrm{min}^{-1}$.

\section{The bonding strength}

In this test, the outer frame size of the metal mould was $70 \times 70 \mathrm{~mm}^{2}$, the inner frame size was $43 \times 43 \times$ $\times 3 \mathrm{~mm}$ according to JGJ/T 70-2009 [23]. The metal mould was placed on the cement mortar block, and then the cement paste was poured into the mould. The sample was cured at $20 \pm 2{ }^{\circ} \mathrm{C}$ and $95+5 \% \mathrm{RH}$ for 7 days. After which, the metal mould was removed. The bonding strength of the samples was calculated by the following Equation 1:

$$
f_{b}=F / A_{Z}
$$

where $f_{b}$ is the bonding strength (MPa), $F$ is the force of the specimen when it fails $(\mathrm{N}), A_{Z}$ is the bonding area $\left(\mathrm{mm}^{2}\right)$.

\section{The FT-IR analysis}

A Fourier transform infrared (FT-IR) spectrometer (Nicolet 380, USA) was utilised to determine the functional group of the hydrated cement with the SCA.

\section{The frost resistance}

The size of samples for the freeze-thawing method was $100 \times 100 \times 400 \mathrm{~mm}$ according to GB/T 259932010 [24]. The samples were soaked in deionised water for $24 \mathrm{~h}$ with a temperature of $20 \pm 2{ }^{\circ} \mathrm{C}$, and then they were taken out of deionised water. The weights of the samples were measured immediately after the surface moisture was removed and noted as $\mathrm{m}_{0}$. A total of 50 cycles were applied in this paper, where one cycle consisted of freezing in $-20{ }^{\circ} \mathrm{C}$ for $4 \mathrm{~h}$, and thawing in $20{ }^{\circ} \mathrm{C}$ for $2 \mathrm{~h}$. the weights of the samples were recorded 
after ever 10 cycles $\left(m_{l}\right)$. The weight loss rate (WLR) of the samples use the following equation to reflect the frost resistance Equation 2:

$$
\mathrm{WLR}=\frac{m_{0}-m_{1}}{m_{0}} \times 100 \%
$$

\section{Dry shrinkage}

The dry shrinkage was determined according to GB/T 50082-2009 [25]. The samples for the dry shrinkage size were $100 \times 100 \times 515 \mathrm{~mm}$. The samples were cured at a temperature of $20 \pm 2{ }^{\circ} \mathrm{C}$ and $95+5 \% \mathrm{RH}$ for 3 days, and then the samples continued to be cured at a temperature of $20 \pm 2{ }^{\circ} \mathrm{C}$ and $65 \pm 5 \% \mathrm{RH}$, for the same time in order begin to measure and record the length of the samples. The dry shrinkage ratio could be evaluated with Equation 3:

$$
\varepsilon_{s t}=\frac{L_{0}-L_{t}}{L_{b}}
$$

where $\varepsilon_{s t}$ was the dry shrinkage ratio when the time was $t$, $L_{b}$ was the length of the permeable concrete $(\mathrm{mm}), L_{0}$ was the initial length of the sample $(\mathrm{mm}), L_{t}$ was the length of the sample at age $t$.

\section{The mechanical properties}

The flexural strength and the compressive strength of the permeable concrete was determined according to GB/T 50081-2003 [26], the samples were tested by using a pressure testing machine (Exceed, E43, USA).

\section{The void ratio tests}

The total void ratio was tested by dividing the difference between the initial mass $\left(M_{1}\right)$ of the specimens under water and the final mass $\left(M_{2}\right)$ determined following the air drying $\left(25 \pm 1{ }^{\circ} \mathrm{C}, 20 \pm 2 \% \mathrm{RH}\right)$ for $24 \mathrm{~h}$ with the volume $(V)$ of the specimens. The interconnected void ratio was measured by dividing the difference between $M_{1}$ and the final mass $\left(M_{3}\right)$ tested following the air curing

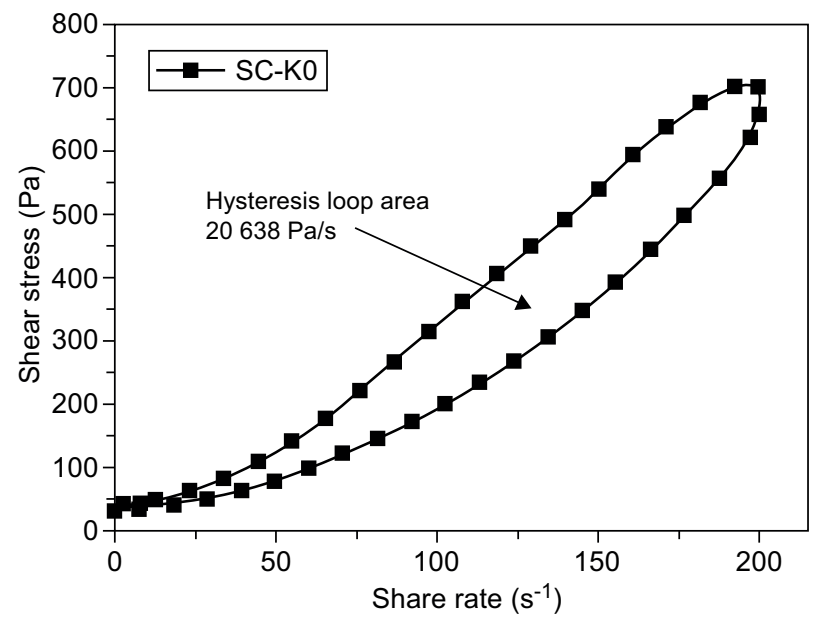

a) $\left(25 \pm 1{ }^{\circ} \mathrm{C}, 95+5 \% \mathrm{RH}\right)$ for $24 \mathrm{~h}$ with the volume. In addition, the density of water $(\rho)$ needed be determined. The equations used to obtain the total void ratio $\left(R_{\mathrm{TV}}\right)$ and the interconnected void ratio $\left(R_{\mathrm{CV}}\right)$ were as follows Equation 4, Equation 5:

$$
\begin{aligned}
& R_{\mathrm{TV}}=\left(\frac{M_{2}-M_{1}}{V \cdot \rho}\right) \times 100 \% \\
& R_{\mathrm{CV}}=\left(\frac{M_{3}-M_{1}}{V \cdot \rho}\right) \times 100 \%
\end{aligned}
$$

\section{The water permeability coefficient (WPC)}

The water permeability coefficient (WPC) of the permeable concrete was measured in accordance with ISO 17785-1, 2016 [27]. The WPC was determined over a period of $50 \mathrm{~s}$ under a water head of $150 \mathrm{~mm}$. The equation used to obtain the WPC was as follows Equation 6:

$$
K r=\frac{H}{h} \times \frac{Q}{A \cdot\left(t_{2}-t_{1}\right)}
$$

where $K r$ was the WPC $\left(\mathrm{cm} \cdot \mathrm{s}^{-1}\right) ; H$ was the length of the specimen $(\mathrm{cm}) ; Q$ was the amount of the drain off water from $t_{1}$ to $t_{2}\left(\mathrm{~cm}^{3}\right) ; h$ was the difference of the water head; $t_{2}-t_{1}$ was the time (s); $A$ was the area of the cross section of the cylindrical specimen $\left(\mathrm{cm}^{2}\right)$.

\section{RESULTS AND DISCUSSIONS}

\section{The rheological properties}

Figure 5 shows the hysteresis loops and the hysteresis loop areas of the cement pastes. As shown in Figure 5, the shear stress increased with the shear rate, which was beneficial for the cement paste to wrap itself on the surface of the aggregate. This phenomenon was different from the ordinary cement paste. The likely

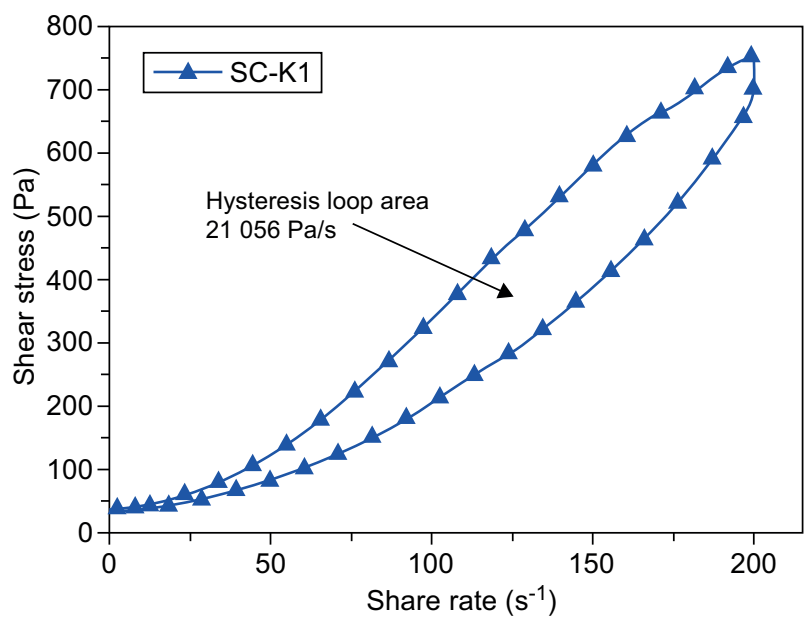

b)

Figure 5. The rheological properties of the cement pastes. (Continue on next page) 


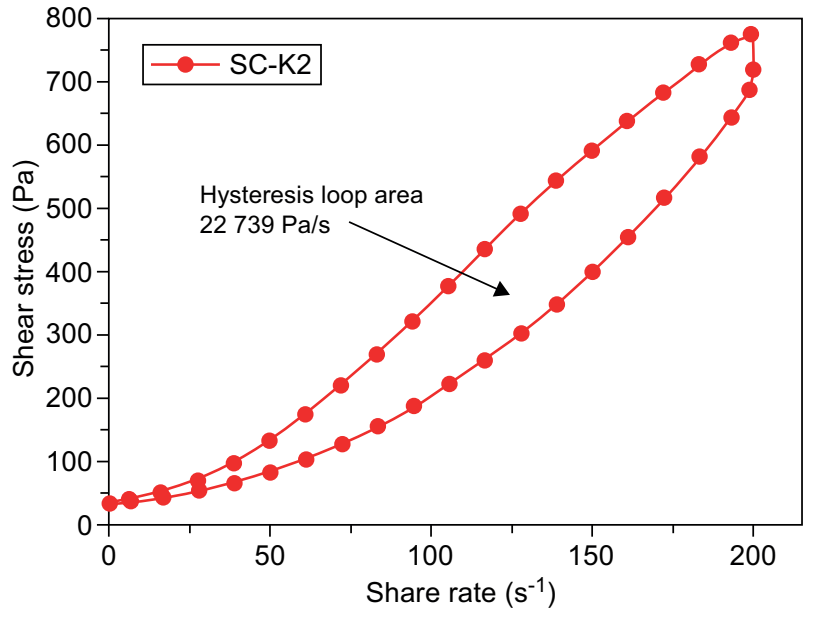

c)

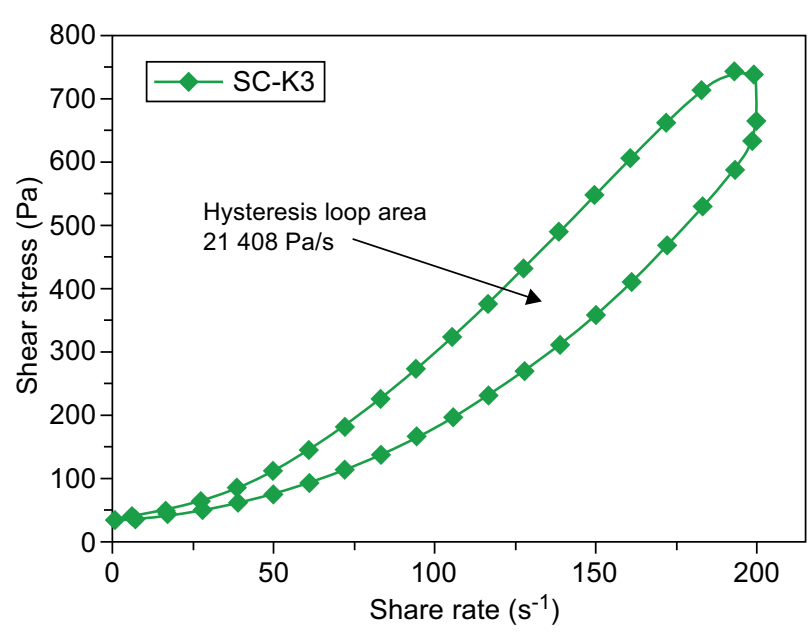

d)

Figure 5. The rheological properties of the cement pastes.

reason was that the addition of the SCA increased the adhesion between the EA and the cement particle. The maximum shear stress increased with an increase in the SCA addition, with a dosage of no more than $2 \%$ of the SCA. When the dosage of the SCA was $2 \%$, the shear stress of SC-K2 reached 777.3 Pa. Compared with the reference of SC-K0, the shear stress increased by $10.3 \%$. It indicated that the addition of the SCA could improve the viscosity of the cement paste. It was beneficial for the cement paste to cover the surface of the aggregates. The area of the hysteresis loop could characterise the workability of the cement paste, which increased with an increase in the SCA content. As shown in Figure 5c, the hysteresis loop area reached $22739 \mathrm{~Pa} \cdot \mathrm{s}^{-1}$. Compared with the reference of SC-K0, the hysteresis loop area increased by $10.2 \%$. The workability of the cement paste was improved [28], when the dosage of the SCA was $2 \%$. The cement paste became easier to wrap around the surface of the aggregates and became more compact.

As shown in the Figure 6, the bonding strength of the cement paste increased from 2.7 $\mathrm{MPa}$ to $3.8 \mathrm{MPa}$

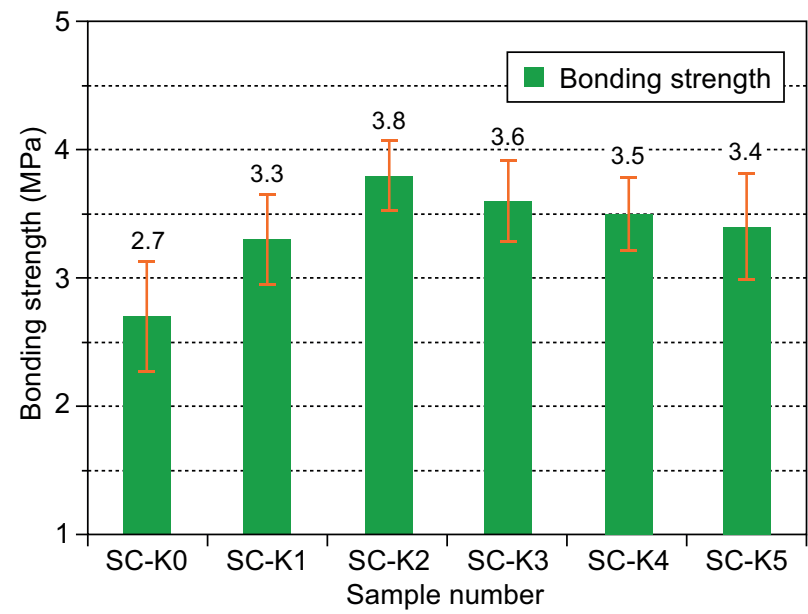

Figure 6. The bonding strength of the cement paste. when the dosage of the SCA was in the range of 0-2\%. SC-K2 reached 3.8 $\mathrm{MPa}$, compared with SC-K0 whose bonding strength increased by $40.7 \%$. When the dosage of the SCA exceeded $2 \%$, the bonding strength of the cement paste decreased. Figure 7 shows the chemical group and organic composition of the cement paste, which were analysed by infrared spectra (FT-IR). The stretching vibration and bending vibration of the $\mathrm{Si}-\mathrm{O}$ bond at $2100 \mathrm{~cm}^{-1}$, the reference $\mathrm{SC}-\mathrm{K} 0$ did not detect the $\mathrm{Si}-\mathrm{O}$ bond. The stretching vibration of $\mathrm{SC}-\mathrm{K} 1$ was formed and though it was not obvious, and SC-K2 has completely formed [29]. The $\mathrm{Si}-\mathrm{O}$ bond could enhance the bonding between the EA and the cement particles. That is why the bonding strength of the SC-K2 cement paste was higher than SC-K1. When the dosage of the SCA exceeded $2 \%$, the Si-O bond formed, but the redundant SCA accumulates on the surface of the cement particles, preventing the cement from hydrating. It explains why the bonding strength of the cement paste decreased when the dosage of the SCA exceeded $2 \%$.

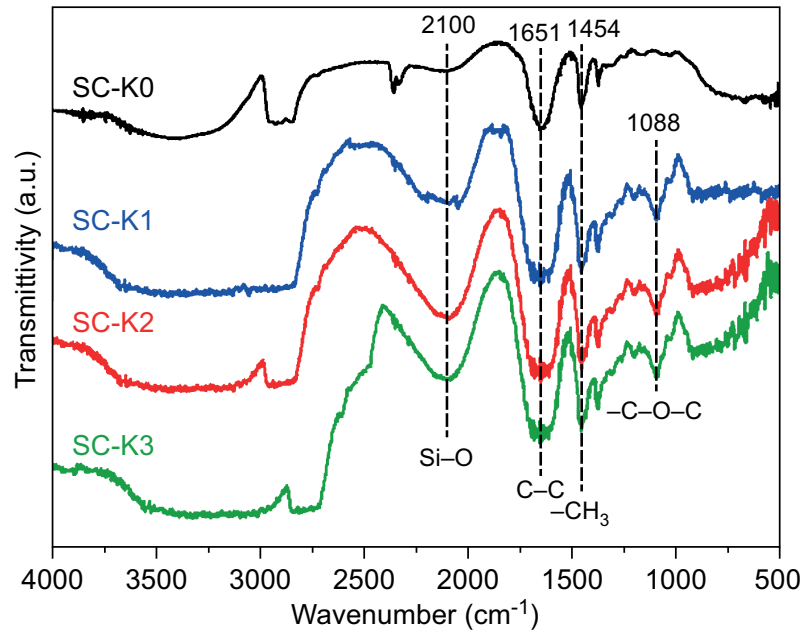

Figure 7. The FT-IR of the cement paste under the different SCA dosages. 
The TG analysis

The results of the TG analysis of the hardened cement paste are shown in Figure 8. In the range of $30-190{ }^{\circ} \mathrm{C}$, the $\mathrm{C}-\mathrm{S}-\mathrm{H}$ gel mainly decomposed. The endothermic peak between $160{ }^{\circ} \mathrm{C}$ and $200{ }^{\circ} \mathrm{C}$ represented the decomposition of the calcium carbo-aluminate $\left(4 \mathrm{CaO} \cdot \mathrm{Al}_{2} \mathrm{O}_{3} \cdot \mathrm{CO}_{2} \cdot 12 \mathrm{H}_{2} \mathrm{O}\right)[33,34]$. The work of Yaqing J. et al. suggested that the calcium carbo-aluminate was produced in the early-age ( $\sim 15 \mathrm{~min})$ hydration of the cement in that the polycarboxylate polymer was adopted [34]. In the range of $420-500{ }^{\circ} \mathrm{C}$, the decomposition of $\mathrm{Ca}(\mathrm{OH})_{2}$ was mainly represented [30]. The content of the $\mathrm{C}-\mathrm{S}-\mathrm{H}$ gel increased when the dosage of the SCA was increased in the range of $0-2 \%$. When the SCA content was $2 \%$, the mass loss of the $\mathrm{C}-\mathrm{S}-\mathrm{H}$ gel of PC-K2 was $9.0 \%$, and the mass loss of the $\mathrm{C}-\mathrm{S}-\mathrm{H}$ gel increased by $2.8 \%$ compared with PC-K0. At the same time, the content of $\mathrm{Ca}(\mathrm{OH})_{2}$ also showed a similar trend. Therefore, when the SCA content was $2 \%$, the effect on the cement hydration was the greatest. This also explains why the bonding strength of the cement paste was highest when the SCA content was $2 \%$, and why it decreases when the dosages of the SCA exceed $2 \%$. The main reason for this was that the excessive SCA accumulation on the surface of the cement particles hinders the contact between the cement particles and the water, thus obstructing the hydration of the cement.

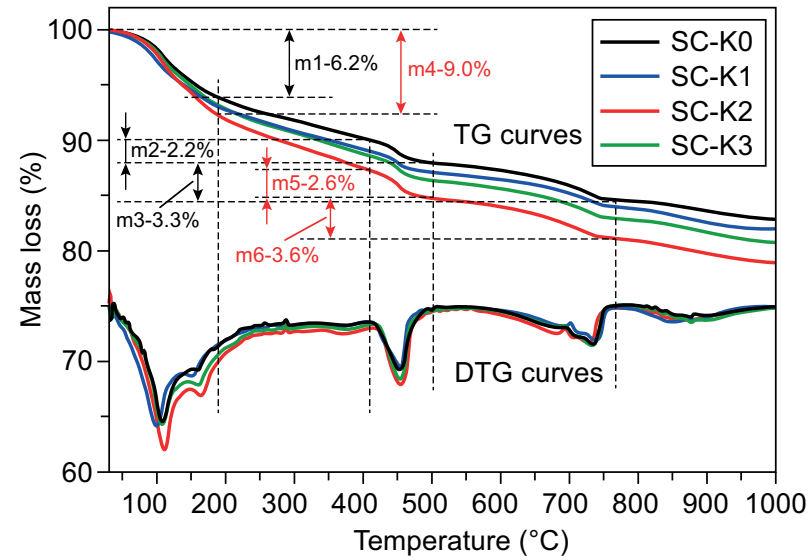

Figure 8 . The results of the TG analysis of the hardened cement paste.

\section{The frost resistance}

Figure 9 shows the mass remaining of the permeable concrete. As shown in Figure 9, the mass remaining rate of the permeable concrete decreased with an increase in the freezing and thawing cycles. When the frost cycles reached 50, the mass remaining rate of sample PC-K0 was $92.7 \%$. At the same time, the mass remaining rates of samples PC-K2 and PC-K5 were $96.9 \%$ and $94.5 \%$, respectively. The results demonstrated that the addition of the SCA could improve the frost resistance of the permeable concrete, due to the excellent bonding performance of the cement paste, when the SCA content was $2 \%$. When the dosage of the SCA exceeds $2 \%$, the frost resistance of the samples was much lower than $\mathrm{PC}-\mathrm{K} 2$. The results are in accord with the bonding strength of the cement paste. At the same time, this also explains why the frost resistance of the permeable concrete first increased and then decreased.

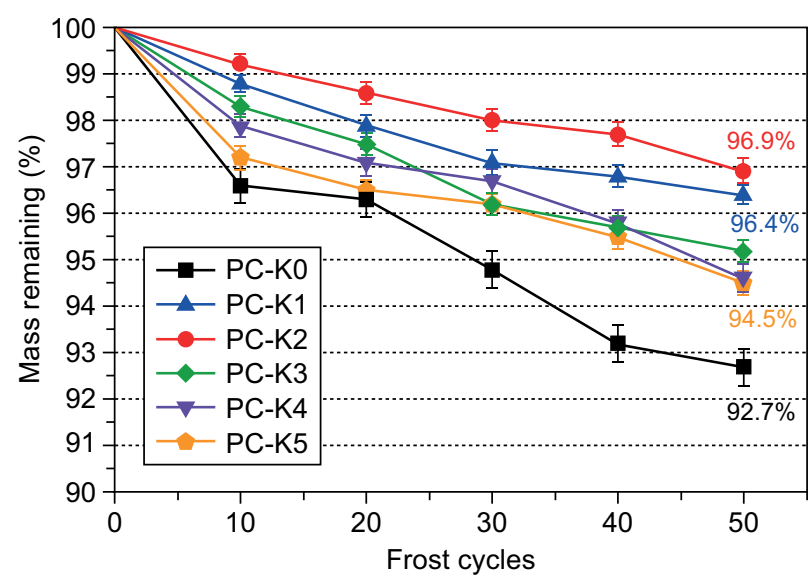

Figure 9. The mass remaining during the fifty freeze-thaw cycles.

\section{The dry shrinkage}

The dry shrinkage development of the permeable concrete is shown in Figure 10. It can be found that the dry shrinkage mainly occurred in the early stage of the hardening, and tended to be stable after 30 days. When the curing time was up to 120-days, the drying shrinkage rate of PC-K5 was $183 \times 10^{-6}$, which was higher than the others. When the dosage of the SCA was $2 \%$, the dry shrinkage of PC-K2 decreased to $122 \times 10^{-6}$, compared with $\mathrm{PC}-\mathrm{K} 5$, where the dry shrinkage rate decreased by $33.3 \%$. Generally speaking, the dry shrinkage of the concrete occurred when the free water evaporated from the pores of the cement paste and the aggregates.

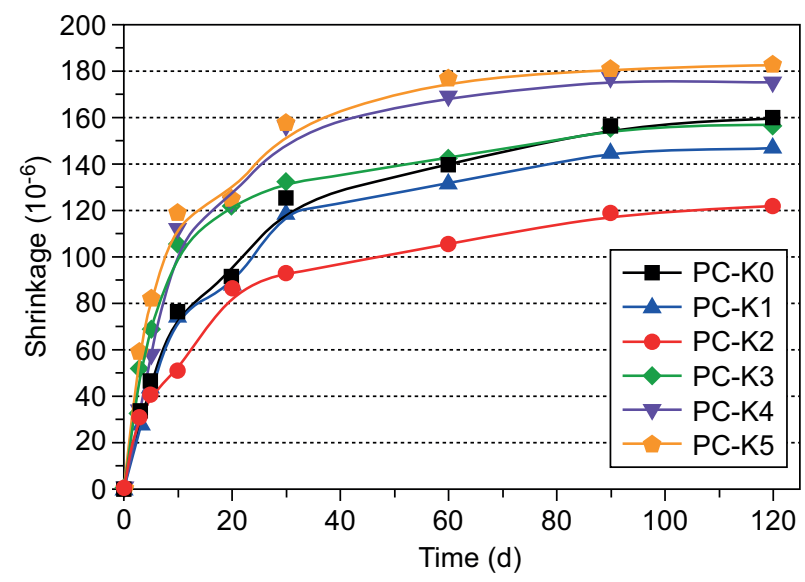

Figure 10. The dry shrinkage of the permeable concrete at the various ages. 
When the dosage of the SCA was $2 \%$, the cement paste was evenly and compactly wrapped around the surface of the aggregate. Therefore, the absorption of the free water in the cement paste by aggregates was hindered, which the dry shrinkage reduced.

\section{The mechanical properties}

The compressive strength and the flexural strength of the permeable concrete is presented in Figure 11. As shown in Figure 11a, the compressive strength of 28-day concrete sharply increased from 16.6 $\mathrm{MPa}$ to 23.8 MPa, when the SCA content went from $0 \%$ to $2 \%$. Compared with PC-K0, the compressive strength of PC$\mathrm{K} 2$ increased by $43.4 \%$. At the same time, the flexural strength of the samples increased with an increase in the SCA content, when the content of the SCA was $2 \%$. The flexural strength of $\mathrm{PC}-\mathrm{K} 2$ reached $6.3 \mathrm{MPa}$. The flexural strength of the samples increased by $31.3 \%$, compared with PC-K0. The increasing trend of the compressive and the flexural strength of the samples is in accordance

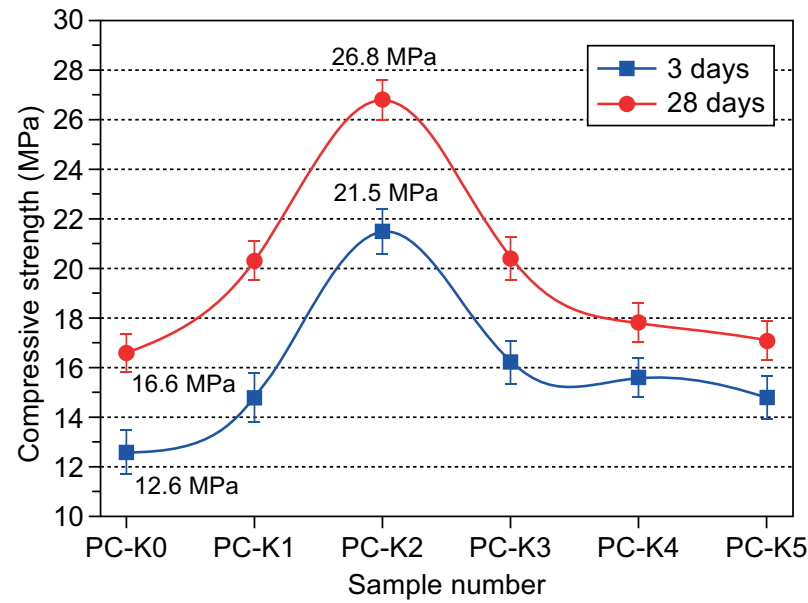

a)

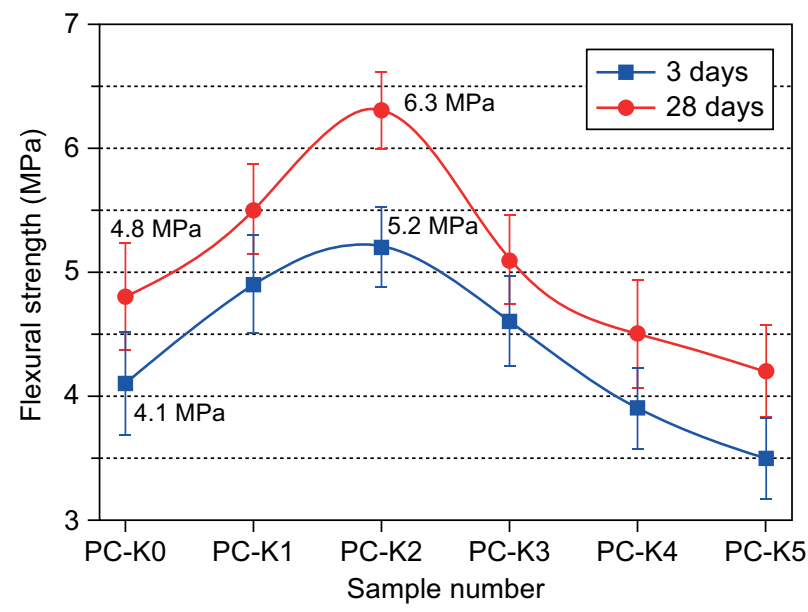

b)

Figure 11. The compressive strength (a) and the flexural strength (b) of the permeable concrete. with the bonding strength of the cement paste, because the mechanical properties of the permeable concrete was decided by the bonding strength of the cement paste of the coarse aggregates. Furthermore, it was also explained that the compressive and the flexural strength of the samples decreased when the content of the SCA exceeded $2 \%$.

The void ratio

As shown in Figure 12, the total void ratio of the samples decreased when the dosage of the SCA was in the range of $0-2 \%$. The total void ratio of $\mathrm{PC}-\mathrm{K} 2$ decreased to $29.8 \%$, which was the lowest amongst all of the experiments. This also explains why the compressive and flexural strength of the samples were the highest, when the SCA content was $2 \%$. The interconnected void ratio of $\mathrm{PC}-\mathrm{K} 2$ was $21.8 \%$, the difference value was $\Delta=7.0 \%$, which was the minimum value when compared to the others. The addition of the SCA reduced the ratio of the harmful and closed pores in the permeable concrete. The reason for this phenomenon is that the cement paste is coated more compactly on the surface of the aggregate and the harmful and closed pores are reduced [31].

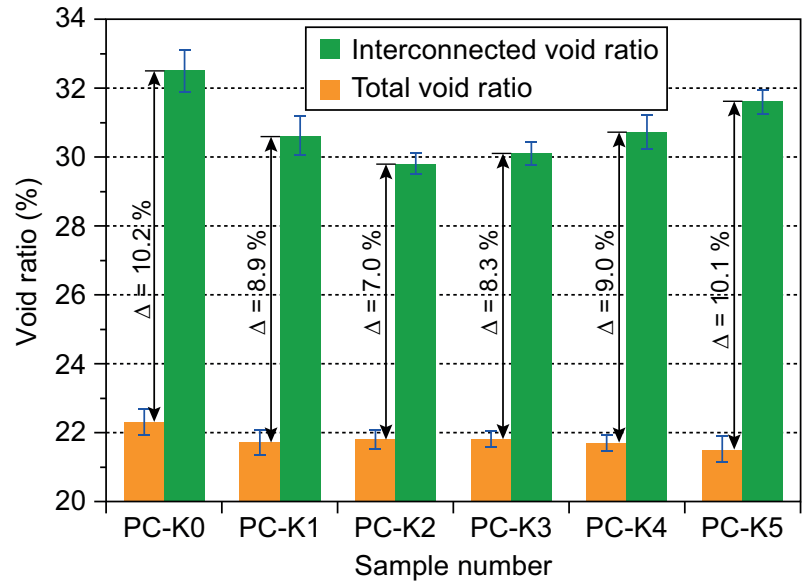

Figure 12. Total void ratio and the interconnected void ratio of the permeable concrete.

The water permeability coefficient (WPC)

As shown in Figure 13a the WPC of the samples decreased, in which the samples contained $2 \%$ of the SCA. Excluding the reference of PC-K0, when the dosage of the SCA was $2 \%$, the WPC of PC-K2 reached $1.66 \mathrm{~cm} \cdot \mathrm{s}^{-1}$, which was the highest amongst all of the methods. The results of the WPC were consistent with the interconnected void ratio. Figure 13b shows the relationship between the interconnected void ratio and the WPC. The correlation coefficient of the interconnected void ratio and the WPC of the permeable concrete is 
0.94846, which suggested that there was a strong linear correlation between the two parameters. It also confirms the conclusion that the WPC of the permeable concrete depends on its interconnected void ratio.

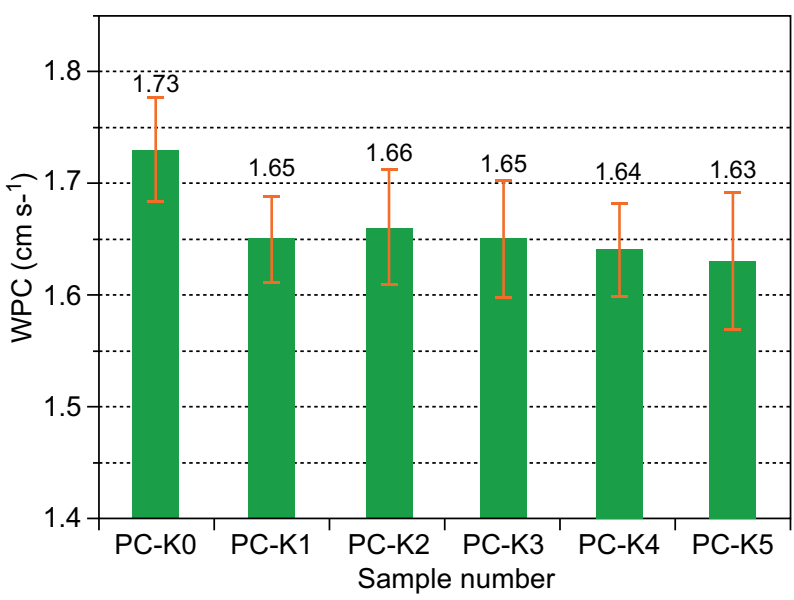

a)

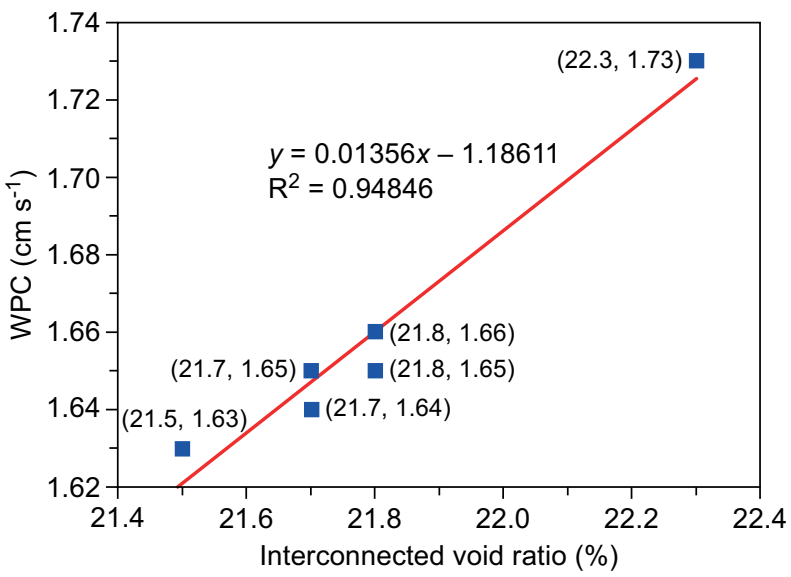

b)

Figure 13. The WPC of the permeable concrete (a) and the relationship between the interconnected void ratio (b).

\section{CONCLUSIONS}

A silane coupling agent (SCA) was utilised to modify the cement paste and permeable concrete with an emulsified asphalt (EA). The rheology and bonding strength of the cement paste and the frost resistance, dry shrinkage, mechanical properties, void ratio and water permeability of permeable concrete were investigated in this paper. The investigation supports the following conclusions:

- Utilisation of an SCA proved to be suitable for the enhancement of the workability and bonding strength of the cement paste in the cases when its addition is no more than $0.14 \%$ (by mass of the cement).
The hysteresis loop area and the bonding strength of the cement paste increased $10.2 \%$ and $40.7 \%$, respectively, at a SCA content of $0.14 \%$.

- With the addition of the SCA, the frost resistance and dry shrinkage of the permeable concrete can be improved. With the SCA dosage of $0.14 \%$, the mass remaining of the permeable concrete increased $4.2 \%$ after the 50 freeze-thaw cycles and reduced $23.8 \%$ at the 120-day dry shrinkage.

- The 3- and 28-day compressive strength and flexural strength of the permeable concrete could be enhanced by the SCA due to a decease in the total void ratio of the permeable concrete. The interconnected void ratio and water permeability coefficient of the permeable concrete decreased by the SCA addition also, and the difference of the total void ratio and interconnected void ratio was reduced by the SCA.

\section{Acknowledgments}

This work was supported by the National Key Point Research and Invention Program of the Thirteenth through grant NO.2016YFC0701000.

\section{REFERENCES}

1. Mohajerani A., Bakaric J., Jeffrey-Bailey T. (2017): The urban heat island effect, its causes, and mitigation, with reference to the thermal properties of asphalt concrete. Journal of Environmental Management, 197, 522-538. doi: 10.1016/j.jenvman.2017.03.095

2. Santamouris, M. (2013): Using cool pavements as a mitigation strategy to fight urban heat island-A review of the actual developments. Renewable and Sustainable Energy Reviews, 26, 224-240. doi: 10.1016/j.rser.2013.05.047

3. Yinghong, Q. (2015): A review on the development of cool pavements to mitigate urban heat island effect. Renewable and Sustainable Energy Reviews, 52, 445-459. doi: 10.1016/ j.rser.2015.07.177

4. Yinghong, Q., Hiller J.E. (2016): Water availability near the surface dominates the evaporation of pervious concrete. Construction and Building Materials, 111, 77-84. doi: 10.1016/j.conbuildmat.2016.02.063

5. Chandrappa A.K., Biligiri K.P. (2016): Pervious concrete as a sustainable pavement material - Research findings and future prospects: A state-of-the-art review. Construction and Building Materials, 111, 262-274. doi: 10.1016/j. conbuildmat.2016.02.054

6. Jing Y., Guoliang J. (2003): Experimental study on properties of pervious concrete pavement materials. Cement \& Concrete Research, 33(3), 381-386. doi: 10.1016/S00088846(02)00966-3

7. Shoude W., Xiaobo Y., Lingchao L. (2013): Effect of aggregate coating thickness on pore structure features and properties of porous ecological concrete. Magazine of Concrete Research, 65(16), 962-969. doi: 10.1680/macr.12.00234 
Yan Z., Li L., Chen M., Lu L., Zhao P., Cheng X.

8. Gelong X., Weiguo S., Xujia H., Zhifeng Y. (2018): Investigation on the properties of porous concrete as road base material. Construction and Building Materials, 158, 141-148. doi: 10.1016/j.conbuildmat.2017.09.151

9. Yiqiu T., Jian O., Yunliang L. (2014): Factors influencing rheological properties of fresh cement asphalt emulsion paste. Construction and Building Materials, 68, 611-617. doi: 10.1016/j.conbuildmat.2014.07.020

10. Laibo L., Mingxu C., Xiangming Z. (2018): Evaluation of the preparation and fertilizer release performance of planting concrete made with recycled-concrete aggregates from demolition. Journal of Cleaner Production, 200, 54-64. doi: 10.1016/j.jclepro.2018.07.264

11. Laibo L., Chenchen G., Shoude W. (2017): Effect of natural zeolite on performance of sulfoaluminate cement-based planting cementitious material. Journal of Wuhan University of Technology-Mater, 32(3), 586-590.

12. Welker A.L., Barbis J.D., Jeffers P. A. (2012): A Side-bySide Comparison of Pervious Concrete and Porous Asphalt. Journal of the American Water Resources Association, 48(4), 809-819. doi: 10.1111/j.1752-1688.2012.00654.x

13. Baoshan H., Shu X., Li G. (2005): Laboratory investigation of portland cement concrete containing recycled asphalt pavements. Cement \& Concrete Research, 35.10, 2008-2013. doi: 10.1016/j.cemconres.2005.05.002

14. Anastasiou E.K., Liapis A., Papachristoforou M. (2017): Life cycle assessment of concrete products for special applications containing EAF slag. Procedia Environmental Sciences, 38, 469-476. doi: 10.1016/j.proenv.2017.03.138

15. Ning X., Akin M., Shi X. (2019): Permeable concrete pavements: A review of environmental benefits and durability. Journal of Cleaner Production, 210, 1605-1621. doi: 10.1016/j.jclepro.2018.11.134

16. Laibo L., Mingxu C., Xiangming Z. (2017): A case of water absorption and water/fertilizer retention performance of super absorbent polymer modified sulphoaluminate cementitious materials. Construction and Building Materials, 150, 538-546. doi: 10.1016/j.conbuildmat.2017.05. 219

17. Laibo L., Xiangming Z., Li Y. (2017): Water absorption and water/fertilizer retention performance of vermiculite modified sulphoaluminate cementitious materials. Construction and Building Materials, 137, 224-233. doi: 10. 1016/j.conbuildmat.2017.01.061

18. Chehong T., Medhat S., Abdurrahmaan L. (2016): Optimizing a test method to evaluate resistance of pervious concrete to cycles of freezing and thawing in the presence of different deicing salts. Materials, 9(11), 878-885. doi: $10.3390 / \mathrm{ma} 9110878$

19. Dalibor K., Tomas V. (2018): Influence of coarse aggregate grain size on frost resistance of concrete. Key Engineering Materials, 776, 37-40. doi: 10.4028/www.scientific.net/ KEM.776.37

20. Hao W., Zhuo L., Beibei S. (2016): Experimental investigation on freeze-thaw durability of Portland cement pervious concrete (PCPC). Construction and Building Materials, 117, 63-71. doi: 10.1016/j.conbuildmat.2016.04.130
21. Lahdensivu J., Mkel H., Pirinen P. (2013): Durability properties and deterioration of concrete balconies of inadequate frost resistance. International Journal of Sustainable Building Technologyand Urban Development, 4(2), 160-169. doi: 10.1080/2093761x.2013.777683

22. GB 175-2007: Common Portland cement. Standardization Administration of the People's Republic of China. Beijing, China. (in Chinese.)

23. JGJ/T 70-2009: Standard for test method of basic properties of construction mortar. Ministry of Housing and UrbanRural Development of the People's Republic of China. Beijing, China. (in Chinese.)

24. GB/T 25993-2010: Permeable paving bricks \& permeable paving flags. Standardization Administration of the People's Republic of China. Beijing, China. (in Chinese.)

25. GB/T 50082-2009: Standard for test methods of long-term performance and durability of ordinary concrete. Standardization Administration of the People's Republic of China. Beijing, China. (in Chinese.)

26. GB/T 50081-2003: Standard for test methods of mechanical properties on ordinary concrete. Standardization Administration of the People's Republic of China. Beijing, China. (in Chinese.)

27. ISO 17785-1, 2016. Testing methods for pervious concrete-part 1: infiltration rate. International Standards Organization. Switzerland.

28. Mingxu C., Laibo L., Yan Z. (2018): Rheological and mechanical properties of admixtures modified 3D printing sulphoaluminate cementitious materials. Construction and Building Materials, 189, 601-611. doi: 10.1016/j.conbuildmat.2018.09.037

29. Lei Y., Min J., Lingchao L., Xiantao S., Xiaobin D. (2019): Properties and micro-structure assessment of building materials based on flue gas desulfurisation gypsum modified by cement and industrial waste. Ceramics-Silikáty, 63, (2), 174-184. doi: 10.13168/cs.2019.0009

30. Pietro U., Petrella M., Tasselli F. (1993): Characterization of fibres from acrylic polymers for cement composites: DSC study. Thermochimica Acta, 227, 135-144. doi: 10.1016/0040-6031(93)80257-B

31. Mingxu C., Lingchao L., Shoude W. (2017): Investigation on the formation of tobermorite in calcium silicate board and its influence factors under autoclaved curing. Construction and Building Materials, 143, 280-288. doi: 10.1016/ j.conbuildmat.2017.03.143

32. Yanlin L., Guangzhong L., Fei L., Laibo L., Lingchao L. (2017): Study on the properties of porous concrete modified by emulsified asphalt. Academic Exchange Conference of China Cement Association, 91-97.

33. Marie M., Jean-François G., Jean A., Jean P. (2011): The influence of gypsum ratio on the mechanical performance of slag cement accelerated by calcium sulfoaluminate cement. Construction and Building Materials, 25, 1298-1304. doi: 10.1016/j.conbuildmat.2010.09.015

34. Yaqing J., Sijia Z., Xiaoyan L., Damidot D. (2010): Early calcium monocarboaluminate hydrate formation in cement paste: effect of polycarboxylate type admixture. Journal of Southeast University, 26, 574-577. doi: 10.3969/j.issn. 1003-7985.2010.04.015 